\title{
Mating behaviour, female receptivity and male-male competition in the intertidal crab Hemigrapsus sexdentatus (Brachyura: Grapsidae)
}

\author{
A. M. Brockerhoff*, C. L. McLay \\ School of Biological Sciences, University of Canterbury, Private Bag 4800, Christchurch 8020, New Zealand
}

\begin{abstract}
Female receptivity and male-male competition were studied in a laboratory population of the New Zealand rock crab Hemigrapsus sexdentatus. Mating only occurred in the few days prior to oviposition, when females had mobile gonopore opercula. After mating, males guarded females constantly and mated with them repeatedly until the females laid eggs. Isolated females remained receptive for significantly longer than females housed temporarily or constantly with males in the laboratory. The duration of female receptiveness can, therefore, vary in relation to the presence of males. Male-male competition was high with frequent attacks on pairs by other males. Large males mated significantly more often than medium and small males, and were more likely to take over a female from another male. However, large and small male $H$. sexdentatus both adjusted the ejaculate size according to the size of the female; i.e. transferred relatively large ejaculates to large females, and were equally able to transfer ejaculates to small and large females during the first mating in the season. Post-copulatory guarding reduced the risk of sperm competition. Although male-male competition appears to be the dominant factor in pair-formation, the ability of females to extend their receptivity in the absence of males, will have an impact on the operational sex ratio, and on the extent of male-male and sperm competition.
\end{abstract}

KEY WORDS: Mating behaviour $\cdot$ Female receptivity $\cdot$ Sexual selection $\cdot$ Male competition $\cdot$ Sperm competition · Ejaculate size

\section{INTRODUCTION}

Reproductive strategies in Crustacea are the result of a complex process in which mating behaviour plays an important role. Although numerous aspects of mate choice, male-male competition and sperm competition (defined as competition between ejaculates of 2 or more males for the fertilisation of the ova of a single female, Parker 1970) have been extensively studied for birds and insects (see reviews of Smith 1984, Anderson 1994, Eberhard 1996, Birkhead \& Møller 1998), these processes are relatively poorly understood for most Crustacea. For example, it is often not known to what extent female choice (i.e. before and after copulation) exists, and how it influences male-male and sperm competition in Crustacea.
Much of the information available on decapod crustacean mating behaviour, sperm storage and sperm competition comes from studies on either commercially important species, such as edible crabs and lobsters, or ocypodid crabs. Studies on commercially important species were often undertaken to understand the reproductive biology of a species to avoid over-exploitation, and to estimate the quantitative and qualitative impact of size-selective or gender-selective fisheries on reproductive success (e.g. Stevens et al. 1993, SainteMarie \& Lovrich 1994, Hankin et al. 1997, Moriyasu \& Benhalima 1998, MacDiarmid \& Butler 1999, SainteMarie et al. 2000, 2002, Kendall et al. 2002).

Mating in Brachyura can either be restricted to a certain period of time when females are morphologically able to mate (e.g. postmoult mating in several Portu- 
nidae and Cancridae) or when their gonopore opercula become temporarily decalcified during the intermoult (e.g. some Grapsidae and Ocypodidae), or it can be unrestricted in time and females are morphologically able to mate at any time during the intermoult (e.g. some Grapsidae, Majidae and Ocypodidae, Hartnoll 1969, Diesel 1991). The timing and duration of female receptivity is important as this determines the operational sex ratio (receptive females per mature males), which has an impact on the extent of male-male competition. In Hemigrapsus sexdentatus, it is the timing and duration of the decalcification of the female gonopore that is important, as this is the time females are receptive and engage in mating activities (see 'Results').

Studies on male-male competition in crabs have demonstrated that male size is often a major factor in male success (e.g. Abele et al. 1986, Donaldson \& Adams 1989, Reid et al. 1994, Moriyasu \& Comeau 1996, Jivoff 1997a, Sainte-Marie et al. 1999). Malemale competition for receptive females typically occurs before or after moulting and during the time of oviposition, and is often evident as pre-copulatory or post-copulatory guarding. Males guard to protect soft-shelled females from predation and cannibalism (when mating is linked to moulting), to prevent other males from mating with the female (Jivoff 1997b), and to prevent sperm competition within the female's spermathecae (see below). The time crustacean males spend guarding the female can be considerable ( $2 \mathrm{mo}$ in the portunid crab Arenaeus cribrarius, Pinheiro \& Fransozo 1999) and costly (reduced growth of $45 \%$ in the amphipod Gammarus lawrencianus, Robinson \& Doyle 1985).

In addition, larger males of Callinectes sapidus have been shown to transfer larger amounts of ejaculate than smaller males and these larger ejaculates contain more sperm (Jivoff 1997a, b; however, see Kendall et al. 2002). Furthermore, male Jasus edwardsii vary the amount of sperm transferred according to female size (MacDiarmid \& Butler 1999). Sperm allocation in Brachyura has so far been poorly studied.

The occurrence of sperm competition seems likely for many brachyuran crabs as females often store enough viable sperm for several broods and through moulting (Greenspan 1982, Paul 1984, Salmon 1987, Fukui 1990, Yamaguchi 1998), and are capable of multiple matings within a single reproductive period (Diesel 1989, Donaldson \& Adams 1989, Orensanz et al. 1995, Jivoff 1997b, González-Gurriarán et al. 1998, Urbani et al. 1998). However, the importance (extent) of sperm competition amongst Brachyura remains largely unknown.

The aim of this study was: (1) to describe the general mating behaviour of Hemigrapsus sexdentatus in the laboratory, (2) to investigate factors that influence the duration of female receptivity, (3) to examine the extent of male-male and sperm competition, and (4) to investigate the relationship of crab size and amount of ejaculate transferred.

In particular, we wanted to test whether females could extend the duration of their receptivity if males are absent or shorten it after they had a certain number of matings. Furthermore, we wanted to test whether male size influences mating success and whether males display behaviour that reduces the risk of sperm competition.

\section{MATERIALS AND METHODS}

Study species. The intertidal crab Hemigrapsus sexdentatus (formerly known as $H$. edwardsii) is endemic to New Zealand, where it occurs on relatively sheltered rocky or stony shores (McLay 1988). H. sexdentatus has 1 short and highly synchronised breeding season every year, in which all mature females lay eggs within about $3 \mathrm{wk}$ (end of March to beginning of April, Brockerhoff 2002). Females of $H$. sexdentatus have gonopores that are covered by opercula. For most of the year, these opercula are calcified and immobile, which inhibits any mating activity. The sex ratio of the mature population is usually slightly female biased; however, the operational sex ratio is highly male biased (Brockerhoff 2002). H. sexdentatus was selected because it is a common species at the study site and it is part of a comparative study of other grapsids.

Hemigrapsus sexdentatus were collected randomly by hand at an intertidal boulder field in Canterbury, South Island, New Zealand ( $43^{\circ} 06^{\prime} \mathrm{S}, 172^{\circ} 53^{\prime}$ E) on 15 January, 15 February, 15 March, 13 April and 18 December 1998; and 18 February, 10 and 21 March 1999, 15 March and 7 April 2000. All crabs were measured (carapace width, $\mathrm{CW}$ ) using Mitutoyo digital callipers to the nearest $0.1 \mathrm{~mm}$, sexed (using the relative abdomen width, females have a wider/broader abdomen than males), and the reproductive stage of the female determined (i.e. ovigerous or not, and whether the gonopore opercula were mobile, see below this section). Mature crabs (CW $>24 \mathrm{~mm}$, Brockerhoff 2002) were taken to the laboratory, where they were held under a 12:12 h light:dark cycle in tanks with circulating seawater of 12 to $15^{\circ} \mathrm{C}$. All but 11 females were non-receptive at the time of capture. Males, non-receptive females and receptive females were kept in separate group tanks and fed opened blue mussels Mytilus galloprovincialis 3 times a week unless otherwise stated. In addition, field observations were carried out during the breeding season in March and April of 1999 and 2000.

To assess female receptivity, which is a prerequisite for assessing the time of mating, the gonopore opercula of all captive females were probed weekly from 
January 1998 and December 1998 until the end of February, and daily in March and April in 1998 and 1999 (which coincides with the time before and during the breeding season). To determine operculum mobility, the abdomen was slightly lifted and 1 of the 2 opercula was probed carefully with fine forceps. When the opercula were mobile, and could be pushed inwards easily like a trapdoor, females were considered receptive. If the opercula were immobile and could not be moved, females were counted as being non-receptive. The duration of female receptivity is defined as the time from the first day a female has mobile gonopore opercula up to the day she lays eggs. Ovigerous females had mobile opercula up to $4 \mathrm{~d}$ after oviposition, but were assumed to be non-receptive, as matings were never observed in the laboratory once a female had laid eggs (see 'Results'). Females were individually marked on their first receptive day with small, numbered bee tags (round plastic discs of $3 \mathrm{~mm}$ diameter, glued to the carapace with cyanoacrynalat glue).

Female receptivity in the absence and presence (temporary or constant) of males. Daily male exposure (short-term trials): To examine the receptivity and mating behaviour of females during short encounters with males, a series of short-term experiments were carried out each day during the receptive period of females. One female and 2 different sized males (small, 29.4 to $45.0 \mathrm{~mm} \mathrm{CW}$, and large 36.1 to $51.7 \mathrm{~mm} \mathrm{CW}$ ) were placed in a tank and their behaviour observed. This experiment also examined whether male size influences male mating success. The large males selected for those experiments were always larger than the female. The mean size difference between large and small males was $9.9 \mathrm{~mm}$. The tank $(25 \times 25 \times 25 \mathrm{~cm})$ was filled with seawater $\left(12\right.$ to $\left.15^{\circ} \mathrm{C}\right)$ to a depth of $15 \mathrm{~cm}$, contained 1 rock for shelter and was kept at ambient room temperature (ca. $19^{\circ} \mathrm{C}$ ). The crabs were observed for a minimum of $1 \mathrm{~h}$ each day. If a female mated within this first hour, the male she mated with was removed after copulation and the remaining 2 crabs were observed for another hour to see whether the second male mated with the female. After a maximum of $2 \mathrm{~h}$, crabs were separated and returned to their group tanks. Males that mated were usually not used in the following $2 \mathrm{~d}$ to avoid sperm depletion and a decrease in male activity; however, it is likely that this species has adapted to a short synchronous mating season by having a large store of spermatophores and seminal fluid (see also 'Results'). Notes were taken on the general mating behaviour, and the frequency and duration of copulation. A total of 71 females were observed during their receptive period, resulting in 297 trials.

Constant male exposure (long-term trials): To examine mating behaviour over the entire receptive period of individual females, long-term experiments were carried out starting on the female's first receptive day and continuing until she laid eggs using continuous video recording (recorder on $24 \mathrm{~h}$ time-lapse mode, $0.18 \mathrm{~s}$ video recording interval). For each trial, 1 receptive female and 3 different sized males (large males, CW $\geq 40.0 \mathrm{~mm}$, medium males, CW 34.0 to $39.9 \mathrm{~mm}$, small males, $\mathrm{CW}<34.0 \mathrm{~mm}$ ) were placed in a glass tank. The tank $(51 \times 25 \times 25 \mathrm{~cm})$ was filled with seawater to about $15 \mathrm{~cm}$ depth, contained 2 rocks for shelter, and was kept in a $15^{\circ} \mathrm{C}$ constant temperature room with a 12:12 h light:dark cycle. Infrared light was used during night hours to allow video recording. The water was changed daily using plastic tubes for carefully draining and refilling to keep disturbance for the crabs to a minimum. Two opened blue mussels were placed in the tank 1 to $2 \mathrm{~h}$ before the water change and then removed just before the tanks were refilled. Fourteen females were monitored continuously resulting in a total of $1909 \mathrm{~h}$ of observation. When the recordings were viewed, the time, frequency and duration of mating, guarding and attacks by males on pairs were recorded.

No exposure to males: To examine the duration of female receptivity in the absence of males, 74 females were kept isolated and their receptivity monitored. Females were held in groups of 20 to 30 under a 12:12 h light:dark cycle in tanks with circulating seawater of 12 to $15^{\circ} \mathrm{C}$.

Other mating behaviour observations. To investigate whether ovigerous females mate, 60 ovigerous females were placed in tanks each with 2 males (large and small males as in short-term experiments above) on the day of egg laying $(n=20)$, and $1(n=20)$ and 2 $(\mathrm{n}=20) \mathrm{d}$ after oviposition and observed for $1 \mathrm{~h}$.

To examine whether males can distinguish between non-receptive and receptive females, a male was placed in a tank with a receptive and a non-receptive female $(\mathrm{n}=22)$, and their behaviour observed for $1 \mathrm{~h}$. In addition, a male was placed in a tank with 2 similar sized, non-receptive females $(n=22)$. This experiment also provided the opportunity to detect pre-copulatory mate guarding prior to the female being physically capable of mating. The glass tanks and general set-up for both experiments was the same as for the short-term experiments (see 'Female receptivity in the absence and presence (temporary or constant) of males').

To test whether the difference in male size influences male success, 1 receptive female and 2 males were placed in a tank and observed for $1 \mathrm{~h}$. Receptive females were randomly chosen on any of their first 4 receptive days. The set-up for this experiment, including the size range of large and small males, was identical as for previously described short-term experiments and data concerning the male-male competition in relation to differences in male size were combined. A 
total of 169 trials where matings were observed were analysed, and included male size differences of 3 to $4 \mathrm{~mm}(\mathrm{n}=26), 5$ to $8 \mathrm{~mm}(\mathrm{n}=43), 9$ to $12 \mathrm{~mm}(\mathrm{n}=55)$, 13 to $16 \mathrm{~mm}(\mathrm{n}=34)$ and 17 to $22 \mathrm{~mm}(\mathrm{n}=11)$.

To examine the pairing pattern with regard to male size in the field, the field site was extensively searched for paired crabs (i.e. males guarding a female, such as a male holding a female with at least 1 of his chelipeds or a male caging a female underneath with his walking legs) during the breeding season in March and April in 1999 and 2000. The carapace widths of the paired crabs and the reproductive state of the female were noted.

Sperm storage and ejaculate size. To investigate whether females mate during each breeding season, the spermathecae of ovigerous females collected from the field in April 1998 and 2000 were examined and weighed. To estimate whether mating activities are similar in the field and in the laboratory, the weight of these spermatheca was compared with those of ovigerous females held and observed in the laboratory (i.e. with a known number of matings), and with females held in field cages in a 1 female to 1 male ratio, during the 2000 breeding season.

To examine whether changes in the weight of the vasa deferentia of males (where spermatophores and sperm fluid are stored) occur during the mating season, males were collected from the field $1 \mathrm{wk}$ before and 2 wk after the breeding season in 2000, and their vasa deferentia removed and weighed.

The amount of ejaculate transferred during the first mating in the season was determined by subtracting the predicted 'empty' spermathecae weight for a female of a given size (derived from regression analysis) from the observed weight of the spermathecae for an identically-sized female. 'Empty' spermathecae are defined as spermatheca of unmated females, meaning they have not mated in the current mating season. However, these 'empty' spermathecae could contain some sperm stored from the previous mating season if the female had mated then. The relationship between the empty spermathecae weight and female CW was determined using linear regression. Similarly, to estimate the size of the second ejaculate, the weight difference between spermathecae which were filled during 2 copulations and the calculated weight of the spermathecae after 1 mating of a given female size was calculated. In 6 cases, negative values were calculated for the second ejaculate, which were not used in the statistical analysis comparing first and second ejaculate. In excluding these 6 negative values, the average weight of the second ejaculate was increased slightly; however, the first ejaculate was still significantly larger than the second (see 'Results').

Crabs were killed by placing them in a freezer at $-15^{\circ} \mathrm{C}$ for about $1 \mathrm{~h}$. The carapace and the upper inter- nal organs were removed to expose the gonads. Both spermathecae of each female were examined and dissected out by a cut close to the gonopore. Spermathecae were considered full when they were clearly visible as 2 large, round, fully filled 'balloons' as soon as the overlying internal organs were removed. The vasa deferentia of the males were removed and weighed. The wet weight of the spermathecae $(2$ combined from each female) and the 2 vasa deferentia was determined to the nearest $0.1 \mathrm{mg}$.

\section{RESULTS}

\section{General mating behaviour}

The gonopore opercula of females were mobile during the intermoult stage a few days before and after oviposition. Only females with mobile gonopore opercula prior to oviposition were observed to mate. Males showed no interest in mating with non-receptive females (i.e. with immobile gonopore opercula). Without courtship, males quickly approached, grasped and manoeuvred receptive females into a female-on-male mating position, which usually only took a few minutes. Subsequently, males guarded females constantly and they mated repeatedly until oviposition unless the pair was disrupted by another male. Males guarded a female by holding one of her walking legs with his chelipeds and/or covering her between his legs. Females appeared inactive during pair formation and postcopulatory guarding, unless they tried to resist the initial mating attempts by the males or tried to escape directly after copulation. Females were also inactive when another male tried to disrupt an established pair. While fighting the other male, the defending male would try to hold the female who got dragged around and pulled back and forth. Sometimes females ran away during the fight, thereby avoiding injury such as the occasional loss of a limb or damage to her carapace.

Males housed with 2 non-receptive females did not approach these females $(n=22)$. When given a choice, males initially had difficulty distinguishing between receptive and non-receptive females. Males approached and briefly held non-receptive females first in 10 out of 22 experiments $(45.5 \%)$; however, they only tried to mate (5 out of 22 ), and succeeded in mating (12 out of 22) with receptive females. Males, therefore, only approached non-receptive females in the presence of receptive females.

In the laboratory, females mated with males that were larger or smaller than themselves. In the field, receptive females were guarded by males, which were all larger than themselves (paired $t$-test: $t=6.266, \mathrm{df}=$ 
$10, p<0.001$ ) and from the upper half of the size range of mature males ( $\geq 39.5 \mathrm{~mm} \mathrm{CW}$ ) (Fig. 1). These receptive females had mobile gonopore opercula, carried no eggs and had full spermatheca indicating that they had recently been inseminated and were being guarded after having mated. There was no correlation between male and female size (Pearson's $r^{2}=0.413$ ). Mating was never observed in the field despite intense searching of the field site and examination of 1490 females during 3 mating seasons. This was most likely due to the fact that mating itself only lasts about $10 \mathrm{~min}$.

All non-receptive females isolated in the laboratory became receptive and eventually laid fertile eggs without mating.

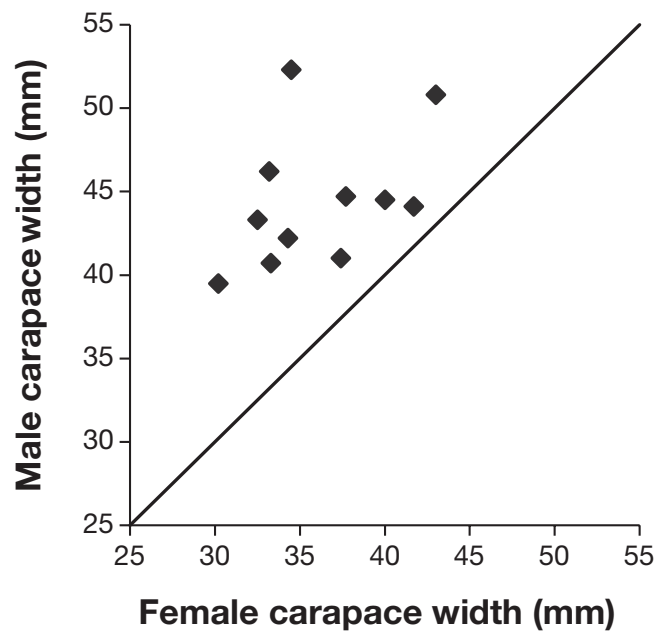

Fig. 1. Hemigrapsus sexdentatus. Size of male and female pairs observed in the field. Line indicates equal male and female sizes

\section{Female receptivity in the absence and presence of males, and mating frequency}

Females were receptive, on average, for $6.3 \mathrm{~d}$ when isolated, for $5.2 \mathrm{~d}$ when males were temporarily present every day, and for $5.5 \mathrm{~d}$ when males were constantly present over the entire receptive period (Table 1). A significant positive correlation was found between the receptivity duration and female size when males were temporarily present. No correlation was found when males were absent or constantly present (Table 1). The duration of female receptivity was significantly longer when males were absent compared to present (ANCOVA: males temporarily and constantly present combined, female size as covariant, $\mathrm{R}^{2}=0.126$, $\left.F_{1,156}=16.57, \mathrm{p}<0.001\right)$.

About half the females mated for the first time on the first day of their receptive period $(47.9 \%)$. Others mated for the first time on the second $(33.8 \%)$, third $(11.3 \%)$ or fourth $(7.0 \%)$ day when males were temporarily present. Mating frequency decreased significantly over the receptive period (Fig. 2). A positive correlation was found between the duration of receptivity and the number of matings when males were temporarily present every day (Table 1). The longer the receptive period, the more often females mated. In contrast, no correlation was found between the duration of receptivity and the number of matings when males were constantly present (Table 1 ). In this case, a longer receptive duration did not significantly increase the number of matings.

The mean number of matings of females was significantly higher when males were constantly present (7.8 matings), compared to when males were only tem-

Table 1. Hemigrapsus sexdentatus. Female receptivity and mating frequency in the absence or presence of males. Mean values given are followed by the standard error of the mean. Results of linear regression are given in parentheses. Superscript letters indicate statistically significant differences. N/A: not applicable

\begin{tabular}{|c|c|c|c|}
\hline Parameter & $\begin{array}{l}\text { Males absent } \\
\qquad(\mathrm{n}=74)\end{array}$ & $\begin{array}{l}\text { Males present } \\
\text { temporarily } \\
(\mathrm{n}=71)\end{array}$ & $\begin{array}{l}\text { Male present } \\
\text { constantly } \\
(\mathrm{n}=14)\end{array}$ \\
\hline Receptivity duration (d) & $\begin{array}{c}6.3 \pm 0.2 \\
\text { (range: } 3 \text { to } 11 \text { ) }\end{array}$ & $\begin{array}{c}5.2 \pm 0.2 \\
\text { (range: } 2 \text { to } 10 \text { ) }\end{array}$ & $\begin{array}{c}5.5 \pm 0.4 \\
\text { (range: } 3 \text { to } 9 \text { ) }\end{array}$ \\
\hline Receptivity duration vs. female size & $\begin{array}{c}\text { no correlation } \\
\left(\mathrm{R}^{2}=0.004, \mathrm{p}=0.590\right)\end{array}$ & $\begin{array}{c}\text { Positive correlation } \\
\left(\mathrm{R}^{2}=0.201, \mathrm{p}<0.001\right)\end{array}$ & $\begin{array}{c}\text { No correlation } \\
\left(\mathrm{R}^{2}=0.035, \mathrm{p}=0.522\right)\end{array}$ \\
\hline No. of matings vs. receptivity duration & N/A & $\begin{array}{c}\text { Positive correlation } \\
\left(\mathrm{R}^{2}=0.185, \mathrm{p}<0.001\right)\end{array}$ & $\begin{array}{c}\text { No correlation } \\
\left(\mathrm{R}^{2}=0.17, \mathrm{p}=0.143\right)\end{array}$ \\
\hline Mating duration (min) & N/A & $\begin{array}{c}9.8 \pm 0.4 \\
\text { (range: } 3 \text { to } 22 ; \mathrm{n}=75 \text { ) }\end{array}$ & $\begin{array}{c}9.4 \pm 0.5 \\
\text { (range: } 3 \text { to } 27 ; \mathrm{n}=109 \text { ) }\end{array}$ \\
\hline Mating duration vs. female size & N/A & $\begin{array}{c}\text { Positive correlation } \\
\left(\mathrm{R}^{2}=0.283, \mathrm{p}<0.001\right)\end{array}$ & $\begin{array}{l}\text { Positive correlation } \\
\left(\mathrm{R}^{2}=0.066, \mathrm{p}=0.007\right)\end{array}$ \\
\hline Mating frequency per female & N/A & $\begin{array}{c}2.7 \pm 0.2^{\mathrm{a}} \\
\text { (range: } 1 \text { to } 6 \text { ) }\end{array}$ & $\begin{array}{c}7.8 \pm 0.8^{\mathrm{b}} \\
\text { (range: } 2 \text { to } 13 \text { ) }\end{array}$ \\
\hline Mating frequency vs. female size & N/A & $\begin{array}{c}\text { No correlation } \\
\left(\mathrm{R}^{2}=0.029, \mathrm{p}=0.153\right)\end{array}$ & $\begin{array}{c}\text { No correlation } \\
\left(\mathrm{R}^{2}=0.005, \mathrm{p}=0.802\right)\end{array}$ \\
\hline
\end{tabular}



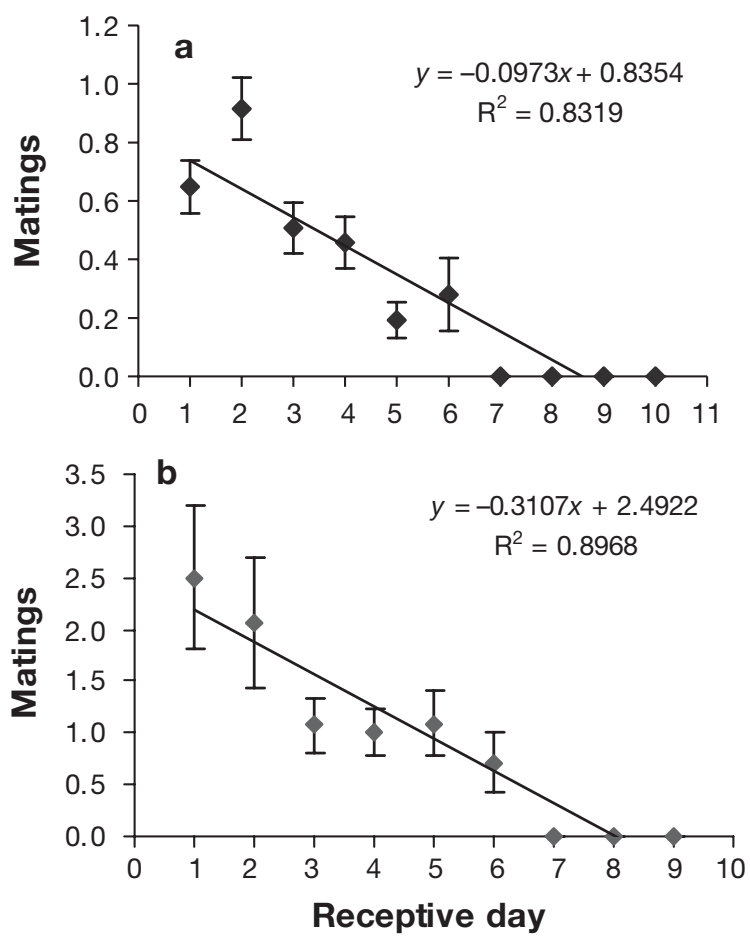

Fig. 2. Hemigrapsus sexdentatus. Mean number $( \pm \mathrm{SE})$ of matings during each day of the receptive period of females. (a) Males temporarily present $(\mathrm{n}=71)$; linear regression: $\mathrm{p}<$ 0.001 ; (b) males continuously present $(\mathrm{n}=14)$; linear regression: $\mathrm{p}=0.001$

porarily present for a short time every day (2.7 matings) (ANOVA: $\mathrm{R}^{2}=0.526, F_{1,83}=92.24, \mathrm{p}<0.001$ ), most likely because the former have more time available for mating. Mating duration was positively correlated with female size, but did not differ significantly when males were temporarily $(9.8 \mathrm{~min})$ or constantly present (9.4 min) (Table 1). Mating duration did not change with subsequent matings (i.e. first, second and third mating of a female). Mating frequency was independent of female size (Table 1).

The time of day (day versus night) had no significant effect on the mating frequency (paired $t$-test: $t=-1.75, \mathrm{df}$ $=13, p=0.104$ ) in the trials where males were constantly present. Out of a total of 109 matings, 43 matings occurred during the day and 66 matings during the night.

\section{Male-male competition}

Males temporarily present

A total of 189 matings were observed in 297 short-term trials that were carried out on each day individually marked females were receptive. Females either did not mate at all $(n=160)$, mated once $(n=85)$ or mated twice
( $\mathrm{n}=52$ ) per trial. Large males were in $54.1 \%$ (46 out of 85 ) of cases the only ones to mate if the female mated only once $\left(\chi^{2}=1.15, \mathrm{df}=1, \mathrm{p}=0.283\right)$, and significantly more often the first male to mate if the female mated twice (37 out of $52,71.2 \%)\left(\chi^{2}=18.62, \mathrm{df}=1, \mathrm{p}<0.001\right)$. The total number of matings was, however, similar for large (98 matings) and small males (91 matings), most likely because the first male to mate was removed after copulation, giving the second (i.e. smaller) male an easier opportunity. Smaller males mated in $44.6 \%$ of the cases when the larger male was removed (37 out of 83), and $27.8 \%$ of the larger males mated after the smaller male was removed (15 out of 54). In both cases, females were likely to mate again when the first male left, indicating high competition for the female as well as high receptivity of the female.

The same trend was found when we investigated the mating frequency of males competing with other males of varying size differences in short-term experiments $(\mathrm{n}=169)$. Large males were again more often the only (61 out of $103,59.2 \%$ ) or first male to mate (47 out of $66,71.2 \%)$, and the total number of matings was similar for large (127 matings) and small males (108 matings). In addition, it was shown that large males generally obtained more matings, almost irrespective of the size difference between the large and small male; i.e. whether it was only 4 or $20 \mathrm{~mm}$ carapace width difference (Fig. 3), suggesting that there is a strong advantage for large males.

\section{Males constantly present}

There was no difference in the duration of matings by males of different sizes (ANCOVA, female size covariate, $\left.\mathrm{R}^{2}=0.001, F_{2,106}=0.059, \mathrm{p}=0.943\right)$. However, larger $(\mathrm{L})$

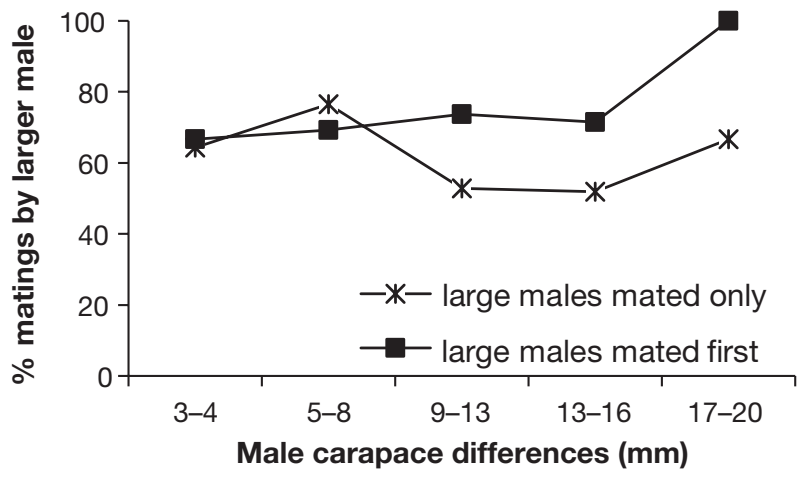

Fig. 3. Hemigrapsus sexdentatus. Percent matings of larger males competing with other males of varying size differences in short-term trials. The male that mated first was removed after copulation and the remaining male was left with the female for another hour. Data shown are from experiments where females mated once $(n=103)$ or twice $(n=66)$ 
males mated significantly more often than medium (M) and small (S) males (ANOVA: relative male size, $F_{2,39}=$ 7.413, $\mathrm{p}=0.002$, Tukey's test: L vs. $\mathrm{M}, \mathrm{p}=0.049$ and L vs. $\mathrm{S}, \mathrm{p}=0.001$ ) (Fig. 4). No significant differences in mating success were found between medium and small males (Tukey's test: $p=0.377$ ). Large males were more likely to be the last to mate before the females laid eggs compared to medium and small males (64\% compared to 15 and $21 \%$, respectively). Male size had a significant effect on being the last male to mate (chi-squared test: $\chi^{2}=6.14, \mathrm{df}=2, \mathrm{p}=0.046$ ). Large males were the last to mate in 9 out of 14 cases compared to 2 times for medium males and 3 for small males.

Frequently, 1 or 2 males simultaneously attacked a pair that was either mating or where the male was guarding the female. A total of 219 attacks on pairs were observed that resulted in either the separation of the pair and the female escaping $(56.2 \%)$, the pair withstanding the attack and remaining together $(36.5 \%)$, or 1 attacking male taking over the female $(7.3 \%)$. Defenders were mostly large males $(51.6 \%)$, followed by the medium $(33.8 \%)$ and small males $(14.6 \%)$, whereas the probability of being an attacker was comparable for all male sizes (small males $28.3 \%$, medium males $40.9 \%$, large males $30.7 \%$ ). Out of the 16 take overs, most were won by large males $(n=12)$, followed by medium $(n=3)$ and small males $(n=1)$.

\section{Sperm storage and ejaculate size}

Isolated females were able to fertilise their ova using at least 1 yr old sperm stored in the spermathecae from the previous mating season. In addition, females must have been able to retain sperm throughout the moulting cycle, as mature females moult before the next breeding season, typically shortly after the larvae hatch (A. M. Brockerhoff pers. obs.).

The spermathecae weight increased with female size whether females were isolated (no matings) (linear regression: $\left.\mathrm{R}^{2}=0.707, F_{1,60}=144.52, \mathrm{p}<0.001\right)$, mated once $\left(\mathrm{R}^{2}=0.837, F_{1,28}=143.44, \mathrm{p}<0.001\right)$ or twice $\left(\mathrm{R}^{2}=0.751\right.$ ， $F_{1,16}=48.38, \mathrm{p}<0.001$ ) in the laboratory or had been collected as ovigerous females (mated unknown number of times) in the field $\left(\mathrm{R}^{2}=0.801, F_{1,52}=209.69, \mathrm{p}<0.001\right)$ (Fig. 5). The number of matings had a significant effect on spermathecae weight (ANCOVA: $\mathrm{R}^{2}=0.804, F_{7,180}=$ $27.235, \mathrm{p}<0.001)$. The spermathecae of unmated females were significantly lighter than females that had mated 1 to 6 times or mated in the field (unknown number of matings) (Fisher's LSD: $p<0.001$ for all). After the first mating, the spermatheca weight increased only slightly with second and further matings (Fig. 5), and the spermathecae weight of females that mated 1, 2 or 3 times were not significantly different from each other

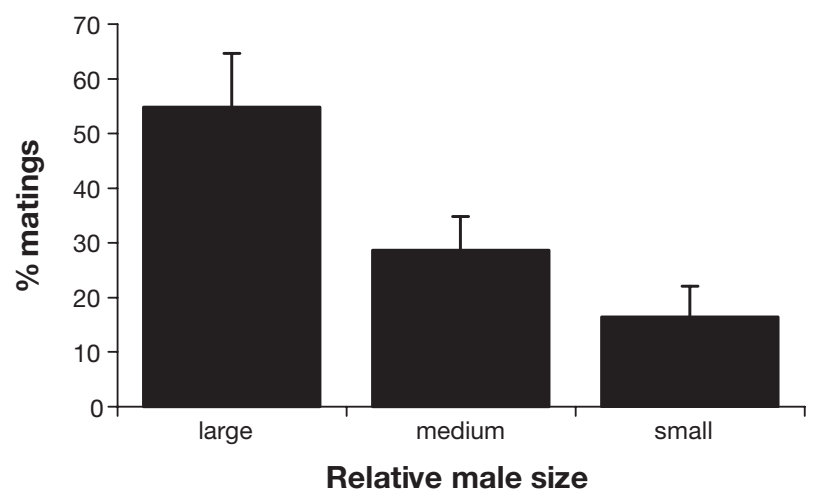

Fig. 4. Hemigrapsus sexdentatus. Relative mating success of large, medium and small males in the presence of 1 female in long-term trials $(\mathrm{n}=14)$
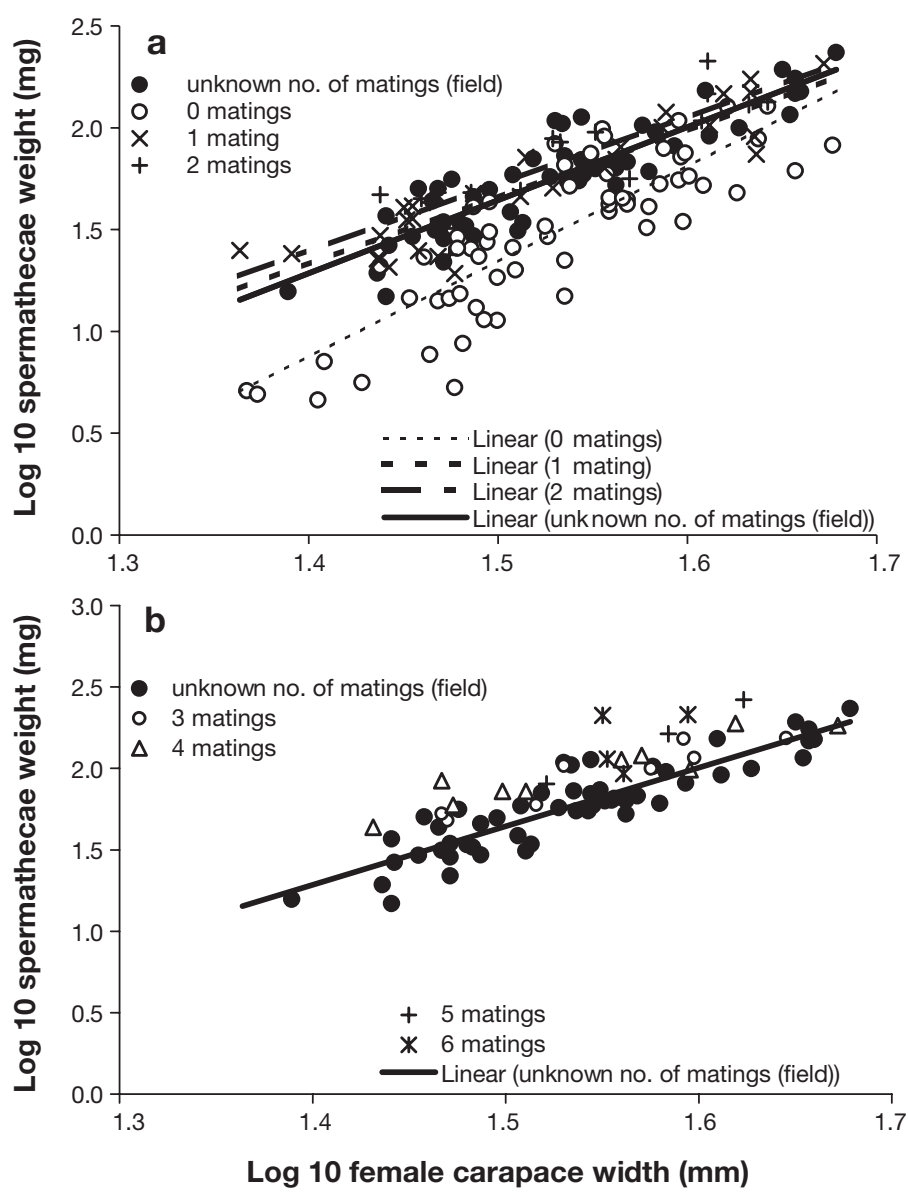

Fig. 5. Hemigrapsus sexdentatus. Spermathecae weight (2 spermathecae combined) of ovigerous females from the field (1998) and laboratory. (a) Field mated females compared to isolated females and females that mated once or twice in the laboratory; (b) field mated females compared to females mated 3 to 6 times in the laboratory. M: number of matings; linear regression equations: no $\mathrm{M}(\mathrm{n}=62), y=4.6948 x-$ 5.6982; $1 \mathrm{M}(\mathrm{n}=30), y=3.3027 x-3.2938 ; 2 \mathrm{M}(\mathrm{n}=18), y=$ $3.319 x-3.2537 ; 3 \mathrm{M}(\mathrm{n}=8) ; 4 \mathrm{M}(\mathrm{n}=11) ; 5 \mathrm{M}(\mathrm{n}=3) ; 6 \mathrm{M}$ ( $\mathrm{n}=3$ ); field (unknown number of matings, $\mathrm{n}=54$ ), $y=$ $3.5948 x-3.7477$ 
(Fisher's LSD: not significant). Furthermore, females that mated 2 and 3 times did not have significantly lighter spermathecae than females that mated 4 times. However, the spermatheca weight of females that mated once was significantly different from females that mated 4,5 or 6 times (Fisher's LSD: $p=0.005, p=0.016$ and $p=0.002$, respectively). It appears, therefore, that the spermathecae are filled almost to capacity during the first mating event in the breeding season (Fig. 5). Subsequent matings only add a small amount to the spermathecae.

All ovigerous females in the field had full spermathecae indicating that they had all mated during the current mating season. Furthermore, field ovigerous females had significantly heavier spermathecae than isolated (unmated) females from the laboratory (Fisher's LSD: $p$ < 0.001) (Fig. 5). There was no difference between the spermatheca weight of field ovigerous females and females that mated once or twice in the laboratory (Fisher's LSD: $\mathrm{p}=0.736$ and $\mathrm{p}=0.114$, respectively). However, field ovigerous females had significantly lighter spermathecae than females that mated 3 and 4 times in the laboratory (Fisher's LSD: $p=$ 0.039 and $p=0.001$, respectively). This suggests that females in the field often mate more than once, but it might be less common that they mate more than twice. Field ovigerous females (uncaged) had significantly lighter spermathecae than females held with males in field cages during the breeding season (ANCOVA: $\mathrm{R}^{2}=0.619, F_{1,45}=34.88, \mathrm{p}<0.001$ ) (Fig. 6). Caged females most likely mated more often than uncaged females, possibly because they were receptive for longer ( 2 to $8 \mathrm{~d}$ ) than uncaged females (less than $1 \mathrm{~d}$ ) or because they could not escape repeated mating attempts by males.

The calculated size of the first ejaculate transferred to 'empty' (=unmated in current mating season) spermathecae increased with female size (linear regression: $\mathrm{R}^{2}=0.564, F_{1,23}=29.80, \mathrm{p}<0.001$ ) (range: $7.6 \mathrm{mg}$ to $79.6 \mathrm{mg}$ ) (Fig. 7a) and was independent of male size (Fig. $7 b)\left(R^{2}=0.004, F_{1,23}=0.087, p=0.77\right)$. This means that males of different sizes were equally able to fill empty spermathecae and that there is no advantage, in this regard, for a female to mate with a larger male. The first ejaculate received by a female with empty spermathecae was significantly heavier than the second ejaculate (ANCOVA: $\mathrm{R}^{2}=0.341, F_{1,34}=7.062, \mathrm{p}=$ 0.012). Observations of the exterior of the female gonopore directly after mating, did not reveal any traces of ejaculate that were spilled.

The weight of the vasa deferentia increased with male size and was not significantly different before and after the mating season for uncaged field males (ANOVA: $\mathrm{R}^{2}=0.733, F_{1,44}=0.11, \mathrm{p}=0.741$ ) (Fig. 8). However, after the breeding season, the weight of the vasa deferentia of caged males held with a female

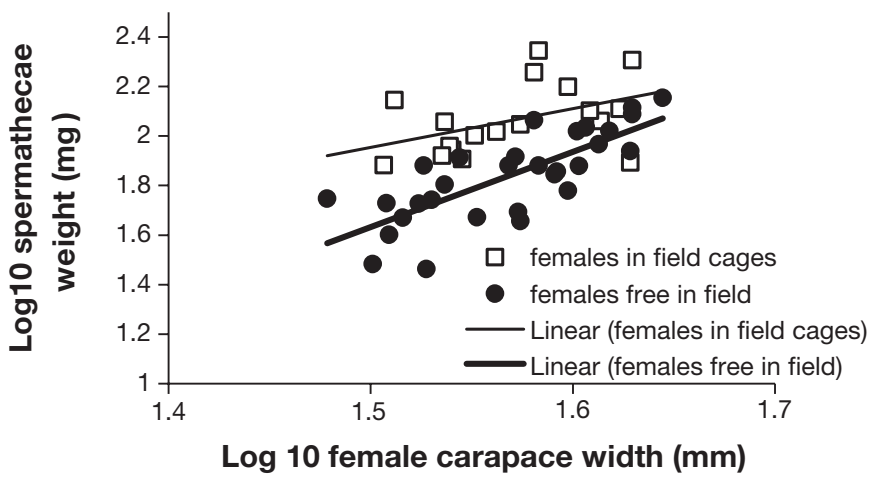

Fig. 6. Hemigrapsus sexdentatus. Spermathecae weight $(2$ spermathecae combined) of ovigerous females from the field and field cages in 2000. Linear regression equations, free field females $(\mathrm{n}=30), y=3.04 x-2.928, \mathrm{R}^{2}=0.589$; caged field females $(n=18), y=1.5622 x-0.394, R^{2}=0.191$
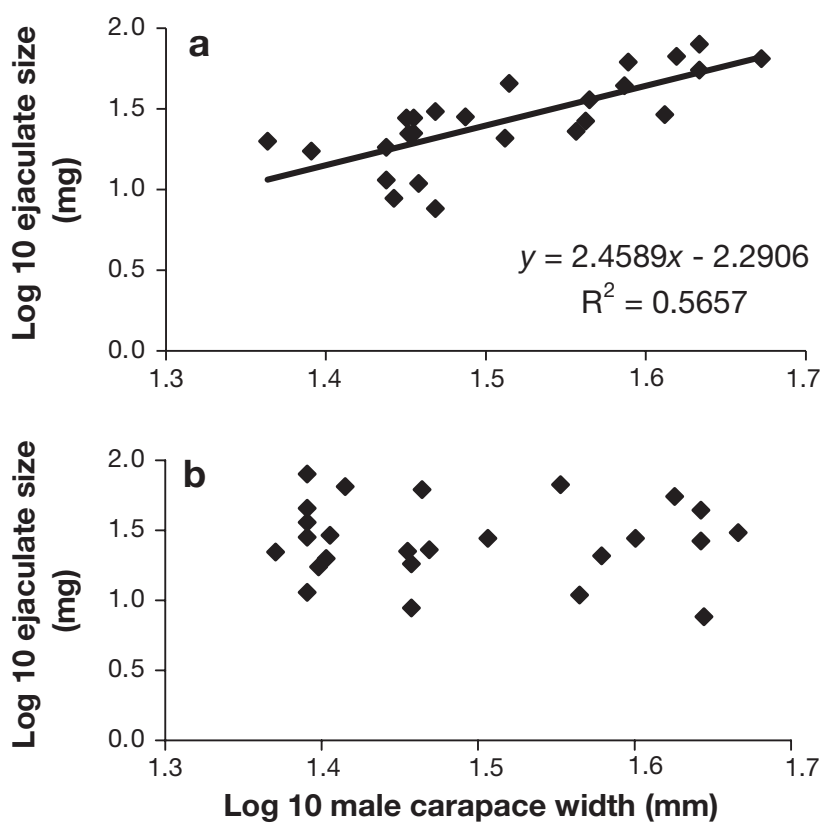

Fig. 7. Hemigrapsus sexdentatus. Relationship between ejaculate size (total ejaculate passed to both spermathecae) and crab size. (a) Size of ejaculate received by females with empty spermathecae; (b) size of ejaculates transferred by males to females with empty spermathecae

were significantly different (lighter) from free field males collected before (ANCOVA: $\mathrm{R}^{2}=0.673, F_{1,38}=$ 20.93, $\mathrm{p}<0.001$ ) and after (ANCOVA: $\mathrm{R}^{2}=0.714$, $F_{1,41}=13.12, \mathrm{p}=0.001$ ) the breeding season (Fig. 8). This indicates that uncaged field males had a large reproductive storage that did not decrease significantly over the breeding season, and that caged males most likely mated more often than uncaged field males. 


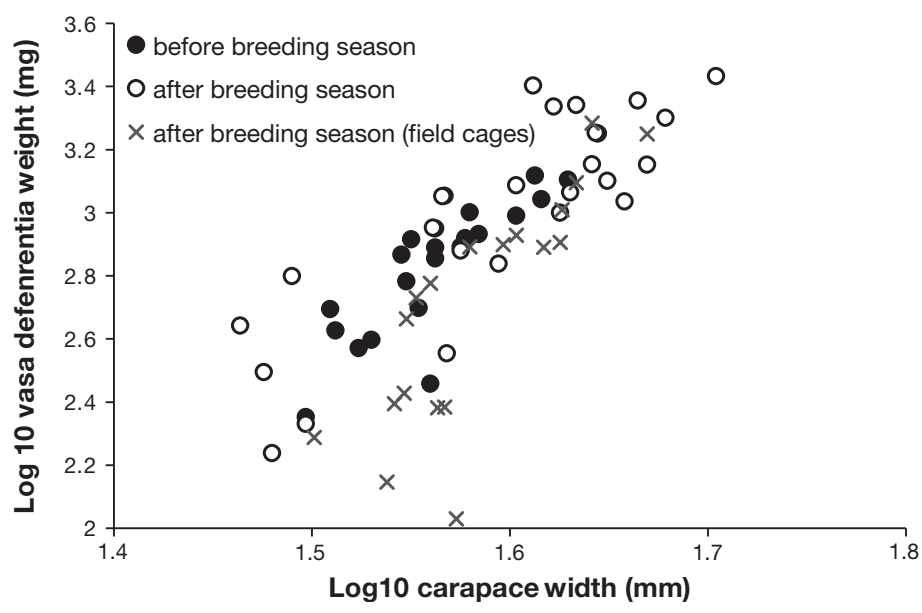

Fig. 8. Hemigrapsus sexdentatus. Weight of vasa deferentia of males before and after the mating season from a field population, and after the mating season from males held in field cages with females

\section{DISCUSSION}

\section{General mating behaviour}

Hemigrapsus sexdentatus mates during the intermoult prior to oviposition when the gonopore opercula are mobile. Other grapsid crabs such as $H$. nudus, H. oregonensis, Sesarma sp., and Gaetice depressus have also been observed mating shortly prior to oviposition (Knudsen 1964, Lindberg 1980, Zimmerman \& Felder 1991, Fukui 1993). We conclude from observations on $H$. nudus and $H$. oregonensis (Knudsen 1964, Lindberg 1980), and our own on $H$. sexdentatus and H. crenulatus (Brockerhoff 2002), that the overall mating behaviour of species within the genus Hemigrapsus is very similar in that: (1) these species show no apparent courtship behaviour, (2) males initiate copulation by approaching females, (3) copulation takes about $10 \mathrm{~min}$, (4) males try to guard females after mating (remains to be shown for species other than $H$. sexdentatus and $H$. crenulatus), and (5) females frequently escape and mate with several males in a short period of time.

Precopulatory mate guarding has been predicted for species with a male-biased operational sex ratio (OSR, i.e. ratio of fertilisable females to sexually active males; Emlen \& Oring 1977) and when mating is restricted to a short, predictable event (see Grafen \& Ridley 1983). However, although the OSR of Hemigrapsus sexdentatus is male biased in the field (Brockerhoff 2002) and female mating is restricted to a short period (mobile opercula), no precopulatory mate guarding was observed. The crab density of these highly mobile crabs in the field is relatively high (3 to 6 crabs $\mathrm{m}^{-2}$ ) (Brockerhoff 2002). A high male-female encounter rate is, therefore, likely and males consequently follow a 'pure searchingintercept' mating system as described by Wickler \& Seibt (1981), except that there is post-copulatory mate guarding (see below).

Females were guarded until oviposition and this occurred whether or not a competitor was present. Post-copulatory guarding in this species is not as necessary as in species where mating occurs with a softshelled, vulnerable female that would need to be protected. As most females mated multiple times in the short and long-term observations, it is therefore likely that post-copulatory guarding in this species is exhibited by the male mainly to deny other males access to the female and, therefore, to reduce the risk of sperm competition. Against this putative benefit of reducing sperm competition, males may have to bear the cost of increased predation risk while guarding the females due to an increase in conspicuousness and predation vulnerability (e.g. Strong 1973, Magnhagen 1991), and must forgo opportunities to mate with other females. An elevated predation risk changes the mating behaviour and courtship of the fiddler crab Uca beebei (Koga et al. 1998) and duration of precopula in the amphipod Hyalella azteca (Strong 1973).

In the laboratory, females mated with males of all sizes, relative to their own size (however, larger males were more successful in a competitive situation), whereas in the field, females were mainly paired with males larger than themselves. According to Ridley (1983), size assortative mating is likely to occur in species where larger females produce larger clutches, larger males are more successful in obtaining mates, and the duration of mating is relatively long. Although the first 2 of these criteria apply to many crabs, with the duration of mating being variable, size-assortative pairing has been found in some crabs (i.e. the ocypodid crabs Uca tetragonon [Goshima et al. 1996] and Uca rapax [Greenspan 1980], the stone crab Hapalogaster dentata [Goshima et al. 2000]), but not in others (i.e. the calappid crab Matuta lunaris [Perez \& Bellwood 1989], Cancer gracilis [Orensanz et al. 1995] and the spider crab Inachus phalangium [Diesel 1988]). Consequently, it has been suggested for I. phalangium that the fitness advantage to males in choosing large females might be offset by the costs of longer search time and the loss of mating opportunities with smaller females (Diesel 1988). A similar situation is likely to apply for Hemigrapsus sexdentatus, where receptive females are spatially and temporally limited even during the peak of the mating season (Brockerhoff 2002). 


\section{Female receptivity in the absence and presence of males, and mating frequency}

Isolated females stayed receptive significantly longer than females that had access to males and had mated. This indicates that females can extend their receptive period to increase the probability of mating if necessary. The same pattern of a longer receptive period of isolated females compared to females held with males was also found for females observed in field cages (Brockerhoff \& McLay 2005). This is an important finding as females can, therefore, influence the operational sex ratio, which in turn will influence the intensity of male-male competition. The duration of receptivity of females was similar when males were either temporarily or constantly present, but females mated more often when males were constantly present. This is not surprising as females had much more time available for mating. In addition, this result shows that females, given the opportunity, mated multiple times and did not reduce the receptive duration after 1 or 2 copulations.

\section{Male-male competition}

Overall, larger male Hemigrapsus sexdentatus were more successful in mating and female guarding. However, a substantial proportion of the matings occurred with males smaller than their competitors. Larger males have relatively larger and stronger chelipeds than smaller males, and this most likely provides them with an advantage in handling the female and during male fights. In addition to being more successful in mating, as is the case with $H$. sexdentatus, larger male Callinectes sapidus were found to pass larger ejaculates to females than smaller males (Jivoff 1997a), which is likely to increase their fertilisation success. However, this was not the case for males of $H$. sexdentatus (see below). In contrast to male size being a strong selective factor, the 3 morphs of the marine isopod Paracerceis sculpta have developed alternative mating strategies in which each morph follows its own reproductive strategy which eventually gives them equal mating success (Shuster \& Wade 1991). In this species, large males defend harems, medium size males mimic female behaviour and morphology, and small males establish themselves in large harems.

\section{Sperm storage and ejaculate size}

In the long-term experiments, large male Hemigrapsus sexdentatus were more often the last to mate before oviposition. This is likely to increase their chance to fertilise the ova, as female $H$. sexdentatus have ventral-type spermathecae where the oviduct and vagina are at the ventral end of the spermatheca (see Diesel 1991). In other species, such spermathecae have been reported to favour the last male's sperm during fertilisation. For example, the last male to mate seals off the rival's sperm and fertilises most of the ova in Inachus phalangium (Diesel 1989, 1991). Similarly, over $90 \%$ of the eggs in the crab Scopimera globosa are fertilised by the last male (Koga et al. 1993). Male Chionoecetes opilio are also advantaged when they are the last to mate, due to the stratification pattern of ejaculates in the female spermatheca (Urbani et al. 1998). However, the storage pattern of the sperm could be disrupted in spermathecae with large loads, which can result in multiple-male paternity in $C$. opilio (Sainte-Marie et al. 2000).

It has been shown for the grapsid crab Metopograpsus messor that changes start to occur within the spermathecae shortly after copulation. Initially, spermatophores are clearly discernible within the spermathecae. After the first day, the spermatophore wall starts to disintegrate and $3 \mathrm{~d}$ after copulation the spermatophore wall starts to completely dissolve, causing spermatozoa to become dispersed in the spermathecal lumen (Anilkumar et al. 1999), which might eventually lead to the mixing of ejaculates. Similarly, spermatozoa within the spermathecae of Chasmagnathus granulata were found not to be stored in discrete packages and it was suggested that spermatozoa from different matings could mix (López Greco et al. 1999). However, the number of matings was unknown in the latter study and could, therefore, not be related directly. Investigations on the short- and long-term pattern of sperm storage are necessary for $H$. sexdentatus (which might involve sperm mixing or stratification), to establish the exact fertilisation process which will determine paternity in this species.

All ovigerous females from the field had full spermathecae, indicating that they all mated during the breeding season. It appears that most females in the field mate once or twice, some possibly 3 or 4 times, based on a comparison with spermathecae weight of females which mated in the laboratory. Females in the laboratory mated between 1 and 13 times in the short and long-term trials, and therefore appeared to mate more often than females in the field, possibly due to a longer receptive period compared to field females. The spermathecae weight increased with female size whether females had mated or not. An increase of spermatheca weight with female size was also observed for Uca lactea (Murai et al. 1987), Callinectes sapidus (Jivoff 1997a), and Macrophthalmus hirtipes (Jennings et al. 2000). Isolated females (in the labora- 
tory) were able to lay fertilised eggs, presumably using stored sperm from the previous mating season.

During the first mating in the season, male Hemigrapsus sexdentatus adjusted the ejaculate size according to the size of the female, i.e. transferred relatively large ejaculates to large females. Similarly, male Panulirus argus vary the amount of ejaculate positively with female size (MacDiarmid \& Butler 1999). Furthermore, large and small male $H$. sexdentatus were equally able to transfer the first ejaculate to small and large females. However, this was not the case for Callinectes sapidus, where smaller males transfer smaller ejaculates than larger males (Jivoff 1997a,b). It has been shown for Chionoecetes opilio and Callinectes sapidus, that larger ejaculates contain more sperm compared to smaller ejaculates (Sainte-Marie \& Lovrich 1994, Jivoff 1997a). Although, we did not examine this relationship for $H$. sexdentatus, it is likely that a similar relationship between ejaculate size and sperm number would be found. In this case, larger males would therefore transfer more sperm to larger females which produce more eggs compared to smaller females.

In Hemigrapsus sexdentatus, the spermathecae were filled almost to their maximum after the first copulation and subsequent matings increased the spermathecae weight only slightly. This could be due to an increased resistance while filling the relatively full spermatheca any further. It appears, therefore, that ejaculate size (transferred to the female spermathecae) decreases with subsequent matings due to the fullness of the spermathecae. Alternatively, males could try to flush out the previous contents to be able to get some of their ejaculate into the spermathecae, which has been reported for insects (see Birkhead \& Møller 1998). However, this is not very likely, because the gonopods are too big to be inserted into the female spermathecae and a narrow vagina probably does not permit flushing of viscous ejaculates.

Furthermore, our assumption that the amount of ejaculate stored by the female represents what was passed to her is also supported by the observations that female Hemigrapsus sexdentatus have no sperm plugs (A. M. Brockerhoff pers. obs.) and females are not likely to be able to flush out unwanted ejaculates because no morphological structures on the spermathecae were observed that would facilitate this. However, it is known that part of the ejaculate of some brachyurans can protrude from the spermathecae, erodes and is lost soon after mating (Hankin et al. 1997), and that in other animal taxa, females can flush unwanted ejaculate from their spermathecae (Pizarri \& Birkhead 2000).

In summary, male Hemigrapsus sexdentatus search for and defend receptive females until they lay eggs.
Although male-male competition appears to be the dominant factor in pair-formation in this species, the ability of females to extend their receptivity in the absence of males will have an impact on the extent of male-male competition and sperm competition.

Acknowledgements. We would like to thank J. V. Briskie for his valuable comments on an earlier version of this manuscript and the suggestions of the anonymous referees. This manuscript was prepared as part of the requirements of a $\mathrm{PhD}$ thesis of A.M.B.

\section{LITERATURE CITED}

Abele LG, Campanella PJ, Salmon M (1986) Natural history and social organization of the semiterrestrial grapsid crab Pachygrapsus transversus (Gibbes). J Exp Mar Biol Ecol 104:153-170

Anderson M (1994) Sexual selection. Princeton University Press, Princeton, NJ

Anilkumar G, Sudha K, Subramoniam T (1999) Spermatophore transfer and sperm structure in the brachyuran crab Metopograpsus messor (Decapoda: Grapsidae). J Crustac Biol 19:361-370

Birkhead TR, Møller AP (1998) Sperm competition and sexual selection. Academic Press, San Diego, CA

Brockerhoff AM (2002) Comparative studies of the reproductive strategies of New Zealand grapsid crab (Brachyura: Grapsidae) and the effects of parasites on their reproductive success. PhD thesis, University of Canterbury, Christchurch

Brockerhoff AM, McLay CL (2005) Factors influencing the onset and duration of receptivity of female purple rock crabs, Hemigrapsus sexdentatus (H. Milne Edwards, 1837) (Brachyura: Grapsidae). J Exp Mar Biol Ecol 314:123-135

Diesel R (1988) Male-female association in the spider crab Inachus phalangium: the influence of female reproductive stage and size. J Crustac Biol 8:63-69

Diesel R (1989) Structure and function of the reproductive system of the symbiotic spider crab Inachus phalangium (Decapoda: Majidae): observations on sperm transfer, sperm storage, and spawning. J Crustac Biol 9:266-277

Diesel R (1991) Sperm competition and the evolution of mating behavior in Brachyura, with special reference to spider crabs (Decapoda, Majidae). In: Bauer RT, Martin JW (eds) Crustacean sexual biology. Columbia University Press, New York, p 145-163

Donaldson WE, Adams AE (1989) Ethogram of behavior with emphasis on mating for the Tanner crab Chionoecetes bairdi Rathbun. J Crustac Biol 9:37-53

Eberhard WG (1996) Female control: sexual selection by cryptic female choice. Princeton University Press, Princeton, NJ

Emlen ST, Oring LW (1977) Ecololgy, sexual selection, and the evolution of mating systems. Science 197:215-222

Fukui Y (1990) Breeding and molting of Gaetice depressus (de Haan) (Brachyura: Grapsidae) under laboratory conditions. Crustac Res 19:83-90

Fukui Y (1993) Timing of copulation in the molting and reproductive cycles in a grapsid crab, Gaetice depressus (Crustacea: Brachyura). Mar Biol 117:221-226

González-Gurriarán E, Fernández L, Freire J, Muiño R (1998) Mating and role of seminal receptacles in the reproductive 
biology of the spider crab Maja squinado (Decapoda, Majidae). J Exp Mar Biol Ecol 220:269-285

Goshima S, Koga T, Murai M (1996) Mate acceptance and guarding by male fiddler crabs Uca tetragonon (Herbst). J Exp Mar Biol Ecol 196:131-143

Goshima S, Kanazawa M, Yoshino K, Wada S (2000) Maturity in male stone crab Hapalogaster dentata (Anomura: Lithodidae) and its application for fishery management. J Crustac Biol 20:641-646

Grafen A, Ridley M (1983) A model of mate guarding. J Theor Biol 102:549-567

Greenspan BN (1980) Male size and reproductive success in the communal courtship system of the fiddler crab Uca rapax. Anim Behav 28:387-392

Greenspan BN (1982) Semi-monthly reproductive cycles in male and female fiddler crabs, Uca pugnax. Anim Behav 30:1084-1092

Hankin DG, Butler TH, Wild PW, Zue QL (1997) Does intense fishing on males impair mating success of female Dungeness crabs? Can J Fish Aquat Sci 54:655-669

Hartnoll RG (1969) Mating in the Brachyura. Crustaceana 16: 161-181

Jennings AC, McLay CL, Brockerhoff AM 2000. Mating behaviour of Macrophthalmus hirtipes (Brachyura: Ocypodidae). Mar Biol 137:267-278

Jivoff P (1997a) The relative roles of predation and sperm competition on the duration of the post-copulatory association between the sexes in the blue crab, Callinectes sapidus. Behav Ecol Sociobiol 40:175-185

Jivoff P (1997b) Sexual competition among male blue crab, Callinectes sapidus. Biol Bull (Woods Hole) 193:368-380

Kendall MS, Wolcott DL, Wolcott TG, Hines AH (2002) Influence of male size and mating history on sperm content of ejaculates of the blue crab Callinectes sapidus. Mar Ecol Prog Ser 230:235-240

Knudsen JW (1964) Observations of the reproductive cycles and ecology of the common Brachyura and crab-like Anomura of Puget Sound, Washington. Pac Sci 17:3-33

Koga T, Henmi Y, Murai M (1993) Sperm competition and the assurance of underground copulation in the sand-bubbler crab Scopimera globosa (Brachyura: Ocypodidae). J Crustac Biol 13:134-137

Koga T, Backwell PRY, Jennions MD, Christy JH (1998) Elevated predation risk changes mating behaviour and courtship in a fiddler crab. Proc $\mathrm{R}$ Soc Lond B 265: 1385-1390

Lindberg WJ (1980) Behavior of the oregon mud crab, Hemigrapsus oregonensis (Dana) (Brachyura, Grapsidae). Crustaceana 39:263-281

López Greco LS, López GC, Rodríguez EM (1999) Morphology of spermathecae in the estuarine crab Chasmagnathus granulata Dana 1851 (Grapsidae, Sesarminae). J Zool Lond 249:490-493

MacDiarmid AB, Butler IV MJ (1999) Sperm economy and limitation in spiny lobsters. Behav Ecol Sociobiol 46:14-24

Magnhagen C (1991) Predation risk as a cost of reproduction. Trends Ecol Evol 6:183-186

McLay CL (1988) Brachyura and crab-like Anomura of New Zealand. Leigh Laboratory Bulletin, no. 22, University of Auckland

Moriyasu M, Benhalima K (1998) Snow crabs, Chionoecetes opilio (O. Fabricius, 1788) (Crustacea: Majidae) have 2 types of spermatophore: hypotheses on the mechanism of fertilization and population reproductive dynamics in the southern Gulf of Lawrence. Can J Nat Hist 32:1651-1665

Moriyasu M, Comeau M (1996) Grasping behavior of male snow crab Chionoecetes opilio (O. Fabricius, 1788)
(Decapoda, Majidae). Crustaceana 69:211-222

Murai M, Goshima S, Henmi Y (1987) Analysis of the mating system of the fiddler crab, Uca lactea. Anim Behav 35: $1334-1342$

Orensanz JM, Parma AM, Armstrong DA, Armstrong J, Wardrup P (1995) The breeding ecology of Cancer gracilis (Crustacea: Decapoda: Cancridae) and the mating systems of cancrid crabs. J Zool Lond 235:411-437

Parker GA (1970) Sperm competition and its evolutionary consequences in the insects. Biol Rev 45:525-567

Paul AJ (1984) Mating frequency and viability of stored sperm in the tanner crab Chionoecetes bairdi (Decapoda, Majidae). J Crustac Biol 4:375-381

Perez OS, Bellwood DR (1989) Observations on the mating behavior of the Indo-Pacific sandy shore crab Matuta lunaris (Forskål), with notes on the reproductive behavior of the Matutinae (Decapoda, Brachyura, Calappidae). Crustaceana 57:1-8

Pinheiro MAA, Fransozo A (1999) Reproductive behavior of the swimming crab Arenaeus cribrarius (Lamarck, 1818) (Crustacea, Brachyura, Portunidae) in captivity. Bull Mar Sci 66:243-253

Pizarri T, Birkhead TR (2000) Female feral fowl eject sperm of subdominant males. Nature 409:681-682

Reid DG, Abelló P, Warman CG, Naylor E (1994) Size-related mating success in the shore crab Carcinus maenas (Crustacea: Brachyura). J Zool Lond 232:397-409

Ridley M (1983) The explanation of organic diversity. Clarendon Press, Oxford, p 1-272

Robinson BW, Doyle RW (1985) Trade-off between male reproduction (amplexus) and growth in the amphipod Gammarus lawrencianus. Biol Bull (Woods Hole) 168: 482-488

Sainte-Marie B, Lovrich GA (1994) Delivery and storage of sperm at first mating of female Chionoecetes opilio (Brachyura: Majidae) in relation to size and morphometric maturity of male parent. J Crustac Biol 14:508-521

Sainte-Marie B, Urbani N, Sévigny JM, Hazel F, Kuhnlein U (1999) Multiple choice criteria and the dynamics of assortative mating during the first breeding season of female snow crab Chionoecetes opilio (Brachyura, Majidae). Mar Ecol Prog Ser 181:141-153

Sainte-Marie B, Sévigny J, Carpentier M (2002) Interannual variability of sperm reserves and fecundity of primiparous females of the snow crab (Chionoecetes opilio) in relation to sex ratio. Can J Fish Aquat Sci 59:1932-1940

Sainte-Marie G, Sainte-Marie B, Sévigny J (2000) Ejaculatestorage patterns and the site of fertilization in female snow crabs (Chionoecetes opilio; Brachyura, Majidae). Can J Zool 78:1902-1917

Salmon M (1987) On the reproductive behavior of the fiddler crab UCa thayeri, with comparisons to U. pugilator and $U$. vocans: evidence for behavioral convergence. J Crustac Biol 7:25-44

Shuster SM, Wade MJ (1991) Equal mating success among male reproductive strategies in marine isopod. Nature 350:608-610

Smith RL (1984) Sperm competition and the evolution of animal mating systems. Academic Press, Orlando, FL

Stevens BG, Donaldson WE, Haaga JA, Munk JE (1993) Morphometry and maturity of paired tanner crabs, Chionoecetes bairdi, from shallow- and deepwater environments. Can J Fish Aquat Sci 50:1504-1516

Strong DL (1973) Amphipod amplexus, the significance of ecotypic variation. Ecology 54:1383-1388

Urbani N, Sainte-Marie B, Sévigny J, Zadworny D, Kuhnlein U (1998) Sperm competition and paternity assurance 
during the first breeding period of female snow crab (Chionoecetes opilio) (Brachyura: Majidae). Can J Fish Aquat Sci 55:1104-1113

Wickler W, Seibt U (1981) Monogamy in Crustacea and man. Z Tierpsychol 57:215-234

Yamaguchi $\mathrm{T}$ (1998) Longevity of sperm of the fiddler crab

Editorial responsibility: Otto Kinne (Editor-in-Chief), Oldendorf/Luhe, Germany
Uca lactea (De Haan, 1835) (Decapoda, Brachyura, Ocypodidae). Crustaceana 71:712-713

Zimmerman TL, Felder DL (1991) Reproductive ecology of an intertidal brachyuran crab, Sesarma sp. (nr. reticulatum), from the Gulf of Mexico. Biol Bull (Woods Hole) 181: $387-401$

Submitted: September 9, 2003; Accepted: November 4, 2004 Proofs received from author(s): March 15, 2005 